\section{Organizational Performance Management at a Strategic Level. Advanced Systems and Tools}

\section{Vasile Cosmin NICULA ${ }^{1}$, Bogdan Narcis FÎRT,ESCU², Ionel BOSTAN ${ }^{3}$}

\author{
${ }^{1}$ Student Ph.D., Bucharest \\ Academy of Economic Studies, \\ Romania, \\ vasilecosminnicula@gmail.com. \\ ${ }^{2}$ Professor, Ph.D., Alexandru Ioan \\ Cuza University of Iasi, Romania, \\ firtescu@,uaic.ro \\ 3 Professor, Ph.D., Stefan cel Mare \\ University of Suceava, Romania, \\ ionel_bostan@yahoo.com
}

\begin{abstract}
Measuring performance is a key element necessary for the operation of the performance management system serving to provide essential feedback to improve the substantiation of decisions within an organization, at all levels: strategic, operational or individual, and thus plays an important role in translating the entity's strategy into results. Performance management systems are formal systems, based in practice on information technology and on procedures used by managers to maintain or to change the structures that ensure the activities of the Organization to obtain better results. Promotion of advanced tools constitutes a real support for management: among the most relevant tools used in performance management, we can mention: strategic planning, enterprise risk management, change management, customer relationship management, knowledge management, quality management. Performance evaluation considers key performance indicators and success factors established by the Organization, which provide the referential in measuring performance. Performance measurement in the missions planned by the internal audit plays an important role in determining whether the objectives of the institutional strategy are met and whether they have materialized into concrete results.
\end{abstract}

Keywords: strategic management; performance measurement; performance management systems; key performance indicators; critical success factors;

How to cite: Nicula, V.C., Firtescu, B.N., \& Bostan, I. (2017). Organizational Performance Management at a Strategic Level. Advanced Systems and Tools. Journal for Ethics in Social Studies, 1(1), 27-38. https://doi.org/10.18662/jess/04 


\section{Introduction}

Performance management is a necessity in substantiating decisions within organizations, at all levels: strategic, operational or individual and plays an important role in translating the entity's strategy into results.

As shown by some authors - see, e.g., Elena Doina Dascălu et al (2016), "performance management is one of the key functions of management, based on a causal model which integrates the component processes with the results in terms of business objectives, resulting in general effects at the organizational, operational or individual level, expressed in terms of effectiveness, efficiency, and economy in the use of funds".

Strategic management - equated to a discipline that deals with the development, implementation, and evaluation of the strategy within an organization - mainly includes designing on different coordinates the Organization: mission, vision, goals, policies, projects, ensuring a clear correlation and connection between all of these projects. At the strategic level, performance management deals with overall organizational objectives. Considering the fact that a decisive role in achieving the objectives of the organizational strategy lies with the employees, to enhance their responsibility a key trend in the last few years is to harmonize the strategic performance management with the individual performance management, such that organizational goals to be reflected in individual goals.

In performance management at the strategic level, a great advantage for the decision-making process is the use of information technology-based solutions that allow for the analysis and interpretation of data and information available to turn business strategy into realistic plans and results.

Whereas performance management at the strategic level is centered on the results of the business and organizational success, the use of monitoring and measuring tools (instruments) represents a decisive selection problem for the management with respect to the spectrum of selection: (a) systems (Balanced Scorecard, Performance Prism), (b) tools (Key Performance Indicators), (c) models for quality and excellence (EFQM Excellence Model, www.efqm.org).

In the public sector, performance monitoring is a cyclical process, focused on increasing the efficiency and effectiveness of services delivered to citizens, which in turn imposes requirements relating to both the expansion (or development) and improvement of processes and services and the identification and use of appropriate tools and techniques to improve performance. 
Performance Management Systems at the strategic level include three key processes: strategy development, strategy implementation and evaluation of strategic management.

\section{State of knowledge in the field and research methodology}

From the scientific point of view, this paper is based on a comprehensive and relevant bibliography (shown in the list of references), that provides basic documentation on the knowledge in the field of performance management in the public sector and in business: specialized documentation, articles, and legal acts, published both in Romanian literature and by foreign sources with a large variety and a multidisciplinary content.

The research was undertaken to identify specific issues of and approaches to organizational performance management at the strategic level, and associated tools and systems fall into the category of applied research and rely on a vast documentation focused on existing models, internationally reported by prestigious professional institutions in areas such as management, audit, information technology.

The documentary research included studies and analysis on the conceptual framework, reference architectures, specific methods, and techniques, as well as peculiarities of the systems and tools for organizational performance management at the strategic level.

Topics addressed are in itself complex and involve theoretical and practical clarifications. In relation to this reality, an important contribution of the paper is the adoption and detailing of a measuring system which relates to the concept of performance based on a set of value-oriented metrics, key performance indicators and on success factors.

An original contribution of the article is treating performance management from an information technology-oriented perspective, which is a topic of study of interest, both theoretically and practically.

Organizational performance measurement plays a very important role in translating the Organization's strategy into results. To this end, the promotion of advanced tools constitutes a real support for management. We note further, selectively, some of the most relevant tools used in performance management, addressing a wide range of topics of interest: (a) Strategic Planning; (b) Balanced Scorecard (collection of key performance indicators); (c) Benchmarking); (d) Change Management Programs; (e) Customer Relationship Management (CRM); (f) Enterprise Risk Management (ERM); (g) Outsourcing. 
The effectiveness of these instruments largely depends on their integration into the organizational management system.

\section{Measuring organizational performance}

The development of a strategic framework of performance management involves three stages: (a) designing a model of strategic management; (b) developing a reporting model associated with the strategy; (c) designing a model of performance in terms of achieving organizational objectives.

Performance measurement is performed as a continuous process of monitoring, evaluation, and reporting (regarding the way an entity has achieved its objectives in relation to the established performance standards), this process being a sub-process of performance management. This subprocess is based on a system of performance indicators, which allows the evaluation of performance, providing an effective support for understanding, managing and improving organizational performance.

Performance evaluation contributes to the substantiation of decisions at all levels (strategic, operational or individual). As a specific task, that is not confined to only the collection of data on performance targets but is, in fact, a management system (which involves identifying deficiencies and assessing conformity towards a referential), also having an important role in improving the performance of the activity (by increasing efficiency and effectiveness).

Performance indicators that can be used by an entity have a great diversity and can be useful and valued in the following activities:

- Setting targets for increasing the efficiency and improving the use of resources;

- Detecting of strengths and weaknesses, areas of risk for the purposes of taking the most appropriate measures for handling situations that threaten performance;

- Self-assessment of performance through robust and relevant indicators and providing evidence of progress in modernizing the Organization;

- Comparison of performance of the Organization with the performance of other organizations - benchmark (benchmarking) and learning the best practices;

- Evaluation and comparison of the results of the organizational structures (individually and overall evaluation), monitoring of the effectiveness and professionalism of functions; 
- Assessing the degree of potential improvement in the use of resources and the determination of the ratio the operating expenses of the organizational structures commensurate with the resources managed;

- Providing support for demonstrating improvements, decisionmaking and performance management.

Improving business performance is subject to a considerable extent of selecting key performance indicators $\left(\mathrm{KPI}^{1}\right)$ and the proper use thereof. KPI indicators reveal trends in the performance of the business, show whether business objectives are appropriate and should consider aspects of the environment in which the entity operates (www.smartkpis.com).

For the public sector or non-profit organizations, the meaning assigned to the key performance indicators is more complex and, in many cases, non-financial in nature (results concerning public policies, improving the quantity and quality of services - for instance, to citizens for public sector and charity beneficiaries of services for non-profit organizations), and/or the net increase in revenue of those for which the services resulting from investments are available.

Within this framework, performance evaluation (determining the efficiency, effectiveness, and cost-efficiency), requires a specific treatment, in accordance with the specific field.

Critical Success Factors $\left(\mathrm{CSF}^{2}\right)$ are key factors on which organizations should focus their attention and efforts to ensure business success (through the achievement of satisfactory results, with a competitive performance in the environment in which they work), as well as to determine what is essential for the future of the business. Identification of CSF provides guidance on the directions the Organization should focus its efforts to strengthen its own capabilities to achieve the objectives associated with those factors.

For example, as generic factors for success are:

(a) alignment between strategy and its implementation;

(b) the creation of a performance-oriented way of thinking;

(c) creating a sense of ownership or responsibility;

(d) using KPIs for bridging the gap between the strategic plan and its implementation;

(e) performance improvement;

(f) the adaptation of best practices to the context of the Organization;

\footnotetext{
${ }^{1}$ KPI - Key Performance Indicators

${ }^{2}$ CSF - Critical Success Factors
} 
(g) implementation of change in order to obtain improved results;

(h) addressing complexity.

Performance monitoring involves periodic evaluation of the objectives established, with the purpose of taking corrective actions in the event of detection of irregularities (of some misconduct), in order to achieve the proposed performance. Risk management through the inclusion of adequate controls in the internal control management system, the definition of clear procedures, known by each evaluator and those evaluated, including periodic assessments of individual performance shall be subject to periodic reviews conducted by the internal audit department.

Through its evaluations, internal audit may issue an opinion on the effectiveness of the improvements made. Performance measurement in the actions planned by the internal audit plays an important role in determining whether the objectives of the institutional strategy are achieved or not or if they materialize into concrete results.

\section{Advanced tools for managing organizational performance}

Bearing in mind that organizational performance management plays an important role in translating strategy into organizational results, promotion of advanced tools (based on information technologies) constitutes a decision-making support.

Performance management tools must be integrated into the organizational management system, and so used that the level of performance achieved should be further developed and improved. Designing, developing, and combining performance management instruments is done - depending on the specifics of your business and the context of use - considering position and priorities defined for performance management.

Choosing an instrument (a tool) should consider aligning with the strategy and be consistent with the organizational structure and culture.

The tools used in performance monitoring should provide basic information for the analysis of the Organization's performance, as well as for future requirements that will generate strategies' improvement and will assure success (www.bain.com).

Based on these considerations, the starting point will be the existence of initial conditions, such as:

(a) a catalog that contains key performance indicators;

(b) information and analyses that indicate possible deviations and risks; 
(c) a performance management tool that proposes typical instances of performance, associated with generic strategic objectives and plans of an organization;

(d) prior performance evaluation (quarterly or annual assessment);

(e) software tools used to support the decision-making process, through data processing and visualization.

Management preferences for certain solutions require custom design and development of systems that incorporate the required functionality.

The following list is a selection of tools (most used) that can be integrated into performance management systems, addressing a wide range of topics of interest:

1. Comparative study (Benchmarking)

2. Strategic Planning

3. Enterprise Risk Management

4. Customer Relationship Management

5. Outsourcing

6. Collection of performance indicators (Balance Scorecard)

7. Change Management

\subsection{Comparative study (Benchmarking)}

The method of the comparative study (benchmarking) involves comparing the performances of own products or processes with those of foreign competitors out of the market and with the best class companies carrying out similar activities.

The use of tools based on the applications of benchmarking contributes to both improving the performance - by identifying and applying best practices demonstrated by reference organizations in the field, for the specific activity -, as well as to winning the strategic advantage.

\subsection{Strategic planning}

Strategic planning represents a complex process which establishes the general and specific objectives of the business and the way these goals can be accomplished, based on an assessment of the potential of the business in line with the business objectives, and with the actions and resources needed to achieve them.

The use of computer tools could constitute an operational solution for the next stages of strategic planning (see the list immediately following), 
thereby facilitating related processes using high-performance storage facilities, processing, and visualization of information. To these are added amenities for the online consultation of some remote data sources.

Here are the steps:

(a) description of the mission, vision, and core values of the Organization;

(b) setting targets and identifying potential business risks and opportunities;

(c) prioritizing business;

(d) analyze the strengths and weaknesses of the Organization;

(e) evaluating alternative strategies;

(f) establishing the business model, definition of stakeholder expectations and setting business objectives;

(g) developing programs, policies, and plans for the implementation of the strategy;

(h) establish organizational structures to support decision-making processes, information systems, and control systems, as well as employment and training;

(i) allocation of resources to develop critical capacities;

(j) planning and response to unforeseen changes in activity or environment;

(k) performance monitoring.

For the public sector, specifically, the institutional strategy underpins the development of the institutional capacity. As pointed out in [3]: "Institutional development needs assessment is the first step in the process of strengthening the capacity of public institutions in Romania. The purpose of institutional development needs assessment is to identify the needs for capacity building and consolidation, as well as to establish the causes that led to their emergence. Institutional development needs assessment is completed through the development of strategies and implementation plans designed so that to determine and demonstrate the values and benefits contributed by the public institution, through the specific activity carried out in Romanian society".

\subsection{Enterprise risk management}

Developing strategic and business decisions by considering the major risks and opportunities management is both an option for the management of losses and disadvantages, as well as for the adoption of alternative strategic growth variants. Risk management based on a proactive approach to protecting assets and organizations must focus on both value 
and losses, and enforces decisions in the light of risk analysis, identifying the approaches well-suited to business specifics.

According to Dascalu \& Nasta (2015) "the risk management function and/or a committee responsible for this purpose facilitates and monitors the implementation of effective risk management practices and assists owners of the risks in defining the exposure to risk and reporting essential information relating to the risk. Compliance function is implemented to monitor specific risks (financial and financial reporting) regarding non-compliance with the applicable regulatory framework" (Dascalu \& Nasta, 2015).

About the public sector, in Romania, the Order no. 400/2015 of the Secretary-General of the Government, for the approval of the Code of Internal Managerial Control of Public Entities, regulates the implementation of the internal managerial control system in public entities. According to the Standard 8 - Risk Management thereof, the head of the public entity shall establish and implement a risk management process to facilitate efficient and effective achievement of that entity's objectives, on the basis of an institution's own strategy concerning the risks it may face, the associated (sub)processes being formalized in a document called the Risk Register.

\subsection{Customer relationship management}

The Customer Relationship Management (CRM) technology allows firms and companies to collect and manage large amounts of data about customers and organize them in databases, from which to develop strategies consistent with this information. The data collected through CRM initiatives relate to the entire lifecycle of customer relationships - from the initial identification of clients to the efforts to win and keep them as long as possible, thus facilitating the adaptation of products to targeted customer segments.

\subsection{Outsourcing}

Outsourcing involves the transfer to third parties, on a contractual basis, of business activities other than the basic ones, which allows a company to concentrate on its specialized skills and powers. The outsourcing decision is based on the assessment of the financial impact that may reduce costs while improving the performance of the activity. Outsourcing offers cost advantages if the supplier can achieve economies of large scale. A complete financial analysis should include the impact of flexibility and increased productivity or decrease in time to capitalize on the market and can be carried out in two directions: 
1. Evaluation of the non-financial costs and benefits of outsourcing. Managers will qualitatively evaluate the benefits and risks of outsourcing. Benefits include the ability to use the external expertise of a specialized contractor and to free up resources dedicated to business activities (other than the core business). A key risk is the growing dependence of the company towards the contractor, thus limiting flexibility in the future.

2. Choosing a partner for outsourcing and contracting relationship. Selection of candidates will be made depending on their proven efficiency and ability (expertise) to carry out similar contracts. The contract must clearly include a specification of service levels (Service Level Agreement).

\subsection{Collection of performance indicators (Balanced Scorecard)}

Balanced Scorecard method establishes a comprehensive set of objectives and performance measurements that can be quantified and evaluated, including the following categories of performance (Folan, Browne \& Jadgev, 2007; Kaplan \& Norton, 1992):

(a) Financial performance (revenues, earnings, return on capital, cash flow);

(b) Performance in relation to the customers (market share, customer satisfaction measurements, customer loyalty);

(c) Performance of the internal business process (productivity, quality measurements, timeliness);

(d) Performance of innovation (percentage of the revenue generated by new products, employee suggestions, the rate of improvement index);

(e) Employee performance (staff morale, knowledge, turnover, demonstrated use of best practices).

\subsection{Change management programs}

Change management programs allow companies to control the installation of new processes to enhance business benefits. These programs involve the development of initiatives for change, implementing initiatives and generate a repeating model (pattern) to ensure continued success in the future change efforts.

Focus on the results of the change has the effect of implementation of major strategic initiatives, in order to adapt to market changes, to customer preferences, to new technologies or to the strategic plans of the competition. 
Continuous monitoring of progress as a result of any changes will confirm if it pursues the planned path or deviations of the direction to implement changes are identified.

\section{Conclusions}

Performance management systems represent formal systems, based on information and procedures, used by managers to maintain or to change the structures that support the activities of the Organization to obtain better results. These systems focus on the analysis of financial information and other developments that are relevant to managerial decision making and implementation thereof and are based on pre-established practices for identifying, measuring, reporting, communication, evaluation, and implementation of corrective action, for the whole life-cycle of the business.

Implementation of performance management systems is influenced by the organizational conditions and by the human factors (their behavior), issues to be considered when designing such a system.

The generic purposes of the system are monitoring, control and/or learning, and its implementation should consider the particularities and specific purpose of the system.

Selection and integration of a system must take into account the appropriateness of strategy, organization structure, and peculiarities. Performance management systems should support and strengthen the performance strategy, future development directions, the granting of rewards.

Implementation of support technologies, such as software tools or applications for data processing and evaluation of results, can increase the chances of achieving high levels of performance maturity, and to reduce reaction time in decision-making processes. These advantages are reflected in particular on issues related to innovation, competitive advantage, and organizational agility.

\section{References}

BAIN \& COMPANY, bttp://wmw.bain.com

Dascălu, E.D. (2015). Exigences de l'evaluation des besoins pour le developpement institutionnel dans le secteur public. Revue Valaque d'Etudes economique, RVEE, 6(2), pag. 79-88.

Dascălu, E.D., \& Nasta, L. (2015). Managerial Accountability - a Key Factor in the Implementation of International Control System. Analele Universității 
Ovidius, Seria Ştiințe Economice, XV(2), pp. 229-235. http://www.rvee.eu/images/2015/no2/9.rvee dascalu.pdf)

Dascălu, E.D., Marcu, N., \& Hurjui, I. (2016). Managementul si monitorizarea performantei in auditul intern pentru sectorul public din România. Amfiteatru Economic, 18(43), pag.460-475.

http://www.amfiteatrueconomic.ro/ArticolRO.aspx?CodArticol=25 52)

Folan, P., Browne, J., \& Jagdev, H. (2007). Performance: Its meaning and content for today's business research. Computers in Industry, 58(7), pp.605-620.

Kaplan, R.S., \& Norton, D.P. (1992). The Balanced Scorecard: Measures That Drive Performance. Harvard Business Review, 199, pp. 71-79.

Ordinul Secretarului general al Guvernului nr. 400/2015 pentru aprobarea Codului controlului intern managerial al entităţilor publice, Monitorul Oficial, Partea I, nr. 444 din 22.06.2015

The EFQM Excellence Model, bttp:// www.efam.org/the-efam-excellence-model The KPI Institute, http:/ / wmw.smartKPIs.com 